\title{
Alveolar Ridge Preservation in the Esthetic Maxillary Zone: Tuberosity Punch Technique of Gingiva and Bone: A Pilot Study
}

\author{
Mustapha Houmani ${ }^{1}$, Nabih Nader ${ }^{2}$, Ziad Salameh $^{3}$, Antoine Berberi $^{4}$
}

\begin{abstract}
Aim: This paper aims to present an alveolar ridge preservation technique, using an autologous punch formed of hard and soft tissues harvested from the tuberosity area.

Materials and methods: Ten residual sockets in the anterior maxilla were filled with a punch of hard and soft tissues harvested from the tuberosity area. Clinical and radiographical data were collected at the surgical extraction time 0 (T0) and 5 months during implant placement (T1), from clinical and radiological measurements using cone-beam computed tomography scans and periapical radiographs. Core biopsy was harvested during implant placement for histological and histomorphometrical analysis.

Results: Clinically, the alveolar ridge presented a mean width of $10.3 \mathrm{~mm}$ before extraction which decreased to $8.85 \mathrm{~mm}$ at T1, where the mean horizontal loss is $1.45 \mathrm{~mm}$ (standard deviation [SD] $1.03 \mathrm{~mm}$ ). The initial ridge mean height was $11.25 \mathrm{~mm}$ and increased to $12.85 \mathrm{~mm}$ after 5 months, where the mean vertical gain is $1.6 \mathrm{~mm}$ (SD $0.65 \mathrm{~mm}$ ). The radiological evaluation shows a reduction in the horizontal dimension with a mean of $1 \mathrm{~mm}$; however, the sockets show stability in the vertical dimensions. Histology showed a new lamellar bone formation with some areas of woven bone. Histomorphometric analysis showed that the percentage of new bone formed was $42.44 \pm 5.54 \%$ and $48.62 \pm 8.66 \%$ of the connective tissue and $8.94 \pm 5.28 \%$ of the residual autogenous bone.

Conclusion: At T1, the extraction sockets showed significantly lower vertical and horizontal bone changes, compared to T0. The described preservation punch technique resulted in greater stability in the horizontal and vertical dimensions after 5 months.

Clinical significance: Clinical and radiological results show that the punch of hard and soft tissue graft reduces hard and soft tissue dimensional alteration after tooth extraction. In addition, using autogenous bone showed histological new bone formation.

Keywords: Alveolar bone, Gingiva, Ridge preservation, Tuberosity.

The Journal of Contemporary Dental Practice (2021): 10.5005/jp-journals-10024-3049
\end{abstract}

\section{INTRODUCTION}

After tooth extraction, alveolar ridge alteration related to bone resorption associated with modification of the structure and composition of the soft tissue can be presumed. ${ }^{1}$

The decrease of bony volume around the extracted tooth is followed by a collapse of the soft tissue. The socket undergoes a natural remodeling process, leading to a new shape of the soft and hard tissues. ${ }^{2,3}$

Ridge dimensional changes will be observed as a result of many mechanisms, including cellular and acellular phenomena. ${ }^{4,5}$ Histologically, the internal part of the alveolar socket wall consists of lamellar bone, which is called a bundle bone. ${ }^{6}$ The width of this bundle bone would be 0.2 to $0.4 \mathrm{~mm}$. ${ }^{7}$ Likewise, for the periodontal ligament and the root cementum, the existence of this lamellar bone is strictly dependent on the presence of teeth. ${ }^{6}$

Ridge bone loss occurs in two stages depending on the bundle bone disappearance and the modeling and remodeling processes, causing external vestibular and lingual wall resorption. ${ }^{4,8}$ Two weeks after extraction, the alveolar bone will lose the periodontal ligament, the blood supply, and the buccal bundle bone that was in contact with the extracted tooth. ${ }^{9}$

Januario et al. ${ }^{10}$ measured the thickness of the facial bone wall in the anterior maxillary region using cone beam computed tomography $(\mathrm{CBCT})$ and found that after dental extraction in the anterior region, the alveolar buccal bone will be resorbed, especially in the more coronal region.

\begin{abstract}
${ }^{1-4}$ Department of Oral and Maxillofacial Surgery, Dental Faculty, Lebanese University, Beirut, Lebanon

Corresponding Author: Antoine Berberi, Department of Oral and Maxillofacial Surgery, Dental Faculty, Lebanese University, Beirut, Lebanon, e-mail: anberberi@gmail.com; aberberi@edu.ul.lb

How to cite this article: Houmani M, Nader N, Salameh Z, et al. Alveolar Ridge Preservation in the Esthetic Maxillary Zone: Tuberosity Punch Technique of Gingiva and Bone: A Pilot Study. J Contemp Dent Pract 2021;22(3):290-297.
\end{abstract}

Source of support: Nil

Conflict of interest: None

Morjaria et al. ${ }^{11}$ showed that the resorption rate is maximal during the first 3 months, and that the ridge vertical dimension decreases, especially in the facial wall. As a result, the therapeutic decision begins before tooth extraction and offers three options: alveolar ridge preservation (ARP), immediate implantation, or spontaneous healing of the alveolar socket.

To achieve better clinical results, it is important to take into consideration both hard and soft tissues. El Chaar et al. ${ }^{12}$ classified the soft and hard tissues in the extraction sockets into three categories, grade I where a simple socket preservation surgery can be applied and grade II and III where there is a need for bone regeneration techniques or bone grafting surgeries. The best time to preserve or reduce hard and soft tissue alteration is during the 
extraction procedure. ${ }^{13,14}$ Numerous studies showed that even with immediate implant placement, ridge resorption will continue. ${ }^{15,16}$

Many techniques for socket preservation have been described in order to reduce the bone volume loss of the extracted site and to maintain the soft tissue dimensions. ${ }^{5}$

Different types of biomaterials, such as autogenous grafts, allografts, and xenografts, were used for socket preservation techniques. ${ }^{17}$ Collagen material has been introduced for the first time as a material for ridge preservation in a controlled trial. ${ }^{18}$

Living cells present in the grafted bone substitute conserve cell viability and promote new vascularization; for this reason, searching for the best grafting materials is important. ${ }^{19,20}$

After graft placement, the full closure of the wound contributes to a lesser amount of horizontal dimensional changes. For this reason, soft tissue management techniques have been proposed. ${ }^{21}$

The aim of this pilot study is to present an ARP technique using a punch harvested from the tuberosity formed of hard and soft tissues and to evaluate clinically, radiologically, and histologically the results.

\section{Materials and Methods}

This nonrandomized prospective pilot study was conducted in accordance with the Declaration of Helsinki ethical principles for conducting research in humans and all patients. The current investigators planned a two-phase surgical approach for socket preservation after tooth extraction followed by dental implant rehabilitation. The first surgical phase consisted of ARP procedure using an autologous punch formed of hard and soft tissues harvested from the tuberosity area.

The second surgical phase consisted of insertion of a dental implant in the reconstructed tooth site. Core biopsies for a histological evaluation were obtained from the implant sites using a trephine bur (outer diameter $3.5 \mathrm{~mm}$, inner diameter $2.7 \mathrm{~mm}$, and length $14 \mathrm{~mm}$ ). Each biopsy site was prepared for implant placement using drills in graduated diameters and under copious irrigation.

\section{Patient Selection}

Study candidates were patients who presented at the Department of Oral and Maxillofacial Surgery of the Lebanese University, during the academic year 2018 to 2019, for extraction of a nonrestorable maxillary tooth associated with dental implant therapy.

\section{Inclusion Criteria}

Patients in need of tooth extraction of the anterior part of the maxilla with adequate prosthetic space for an implant and crown placement and presenting a grade I alveolar socket ${ }^{12}$ with enough existing bone in volume in the tuberosity area were included in this study. Clinical and radiological findings (intraoral and CBCT) were thoroughly discussed with every patient, and all available treatment options were explained.

\section{Exclusion Criteria}

Patients with a history of systemic diseases, chronic steroid therapy, bisphosphonate intake, uncontrolled diabetes, bruxism, smoking, uncontrolled periodontal disease, or grade II and III alveolar sockets ${ }^{12}$ were excluded from the study.

Ten patients (eight males and two females, mean age: 45 years) were enrolled in the study and were asked to sign an informed consent before admission into the study.

\section{Surgical Extraction}

Surgical anesthesia was induced via local infiltration with $4 \%$ articaine hydrochloride and epinephrine $(1 / 100,000)$ (Septanest; Septodont, United Kingdom). Prophylactic antibiotic was based on amoxicillin with clavulanic acid $1 \mathrm{gm}$ bid for 7 days, starting with $2 \mathrm{gm} 1$ hour before surgery or $600 \mathrm{mg}$ clindamycin in case of allergy to penicillin, followed by $1 \mathrm{gm} / 300 \mathrm{mg}$ twice daily for 5 days. Analgesic medication ibuprofen $600 \mathrm{mg}$ was also prescribed 1 hour before surgery and one tablet in case of pain after surgery. The patients were advised to rinse their mouths with $0.12 \%$ chlorhexidine gluconate oral rinse (PerioGard; Colgate-Palmolive, Guildford, United Kingdom) tid for 15 days.

Before extraction, the buccolingual and mesiodistal dimensions of the tooth were recorded clinically and radiologically with a periodontal calibrated probe.

After having appropriate measures, the harvesting site was chosen from an edentulous posterior region in the maxilla. A mechanical blade punch trephine was chosen in relation to the obtained measurements.

A surgical atraumatic extraction was performed with a minimally invasive procedure using periotomes to cut the periodontal fibers; luxation was performed gently with a small straight elevator to mobilize the tooth. Then, by using adequate forceps, slow and limited movements of rotation were performed and then the tooth was pulled out from the socket with minimum damage to the surrounding soft and hard tissues.

After tooth extraction, any granulation tissue inside the socket was being removed using a small Lucas curette. The extraction socket was irrigated with normal saline and then packed with gauze soaked in normal saline, which was left in situ for 5 minutes.

A periodontal probe was used to identify the integrity of the socket walls.

Subsequently, measurements of the alveolar bone height and width (Fig. 1A) were necessary for harvesting the appropriate punch dimensions of hard and soft tissues. Accordingly, a second mechanical complementary punch set composed of two parts was selected (Fig. 1B). The first part with an appropriate diameter drill is used to prepare a punch bed inside the socket. The second part is a bone trephine used for harvesting the bone graft that will exactly fit the already prepared recipient site (Fig. 1C).

A periotome was used to pull out the material (Fig. 1D) which was placed and inserted into the defect under careful pressure (Fig. 1E) and secured using interrupted monofilament 6-0 sutures Ethilon 6/0; Ethicon Johnson \& Johnson, Somerville, New Jersey).

Finally, an absorbable collagen material used as a hemostatic agent (CollaPlug; Zimmer Biomet Dental) was placed in the posterior region at the donor site and secured with simple stitches.

\section{Clinical and Radiologic Follow-up}

Patients underwent follow-up clinical examinations weekly during the first postoperative month and monthly thereafter until reentry surgery.

Clinical evaluation of the cases was done, and the recordings were taken at 1, 2, 4, 8, and 10 weeks, respectively; the linear clinical scores were performed according to the healing index that contains different criteria; the scores characterizing soft tissue healing are assessed from 1 to $5: 1$ indicating very poor healing, 2 poor, 3 good, 4 very good, and 5 excellent healing. ${ }^{22}$ 

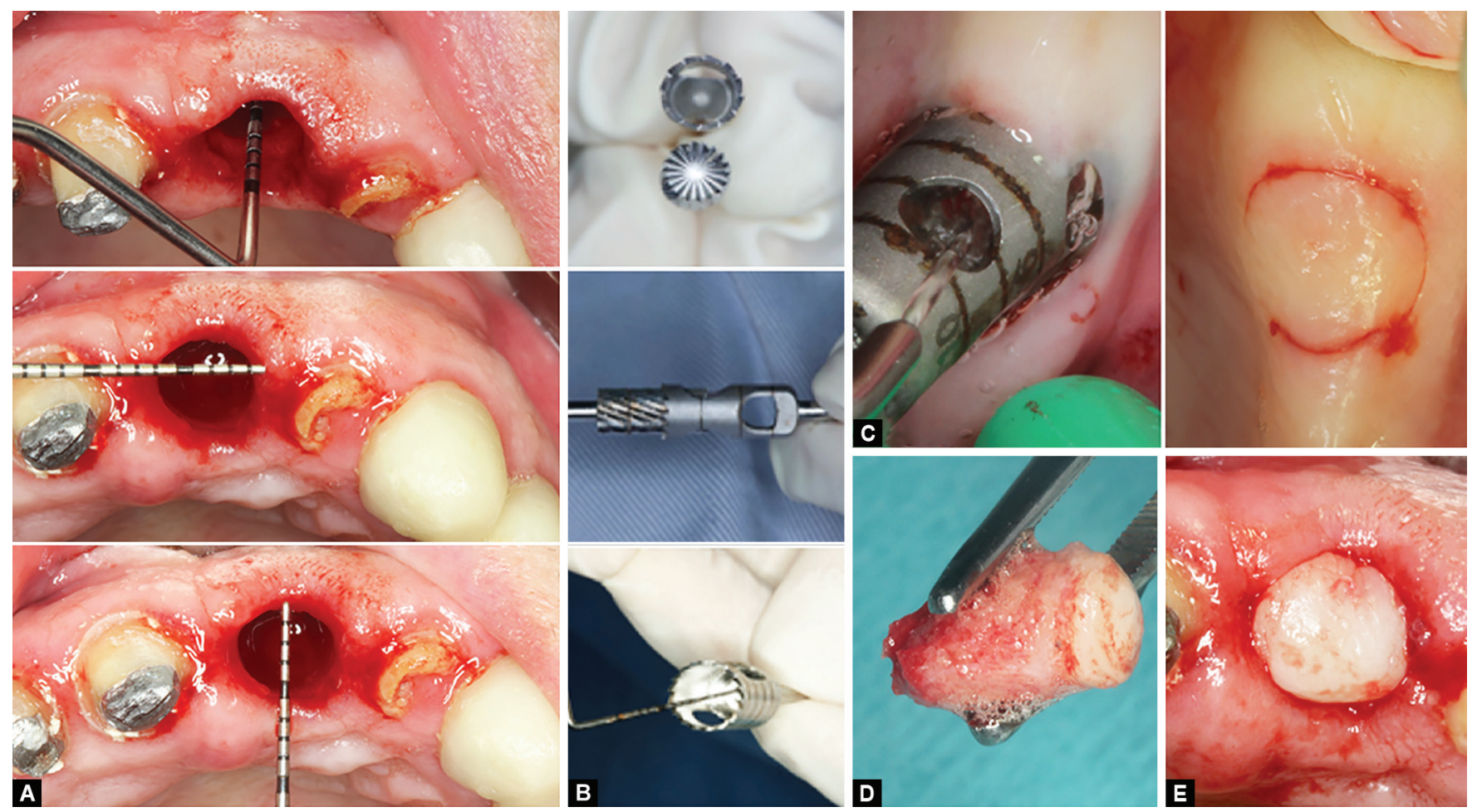

Figs 1 A to E: (A) Socket measurements: in depth, mesiodistal and buccal-palatal; (B) Punch set: bone and tissue parts; (C) Punch application in the tuberosity; (D) Harvesting hard and soft tissues; (E) Placement of the harvested tissue within the socket

Ridge dimensions, measured with a calibrated periodontal probe, were clinically evaluated before extraction (T0) and after 5 months (T1).

Postoperative intraoral radiographs, panoramic radiographs, and $\mathrm{CBCT}$ images were taken at TO (day of tooth extraction) and after 5 months (T1). For CBCT at T0, it was taken within 24 hours of the surgery and 5 months after with a resolution of $0.4 \mathrm{~mm}$ (scan time 17.5 seconds, $90 \mathrm{kV}, 5 \mathrm{~mA}$ ). The findings were analyzed on a computer with a calibrated monitor using the reconstruction software i-CAT.

CBCT cuts (cross-sectional, axial and sagittal view, and panoramic) were analyzed using Dentascan software; 3D reconstruction cuts (para-axial cuts) were evaluated at T0 and T1. The radiographic evaluation was based on the radiological parameters, using reference points and lines at T0 and T1 as described by Das et al. ${ }^{23}$ (Figs $2 \mathrm{~A}$ and $\mathrm{B}$ ).

\section{Implant Placement Surgery}

After 5 months of healing, a reentry procedure was planned to place the implants using the same analgesia technique and medications cited above. Postoperative periapical radiography was taken immediately after punch placement and 5 months later. Clinical and radiological measurements were repeated with the same standards. A primary intention full-flap closure was performed using interrupted sutures.

During implant surgery, a flap was elevated and core biopsies were removed during site preparation from the implant site using a trephine bur, and the implant was placed in correct location (Tapered Screw-Vent; Zimmer Dental, ranging from 11.5 to $13 \mathrm{~mm}$ in length and $4.1-4.7 \mathrm{~mm}$ in diameter) (Figs $3 \mathrm{~A}$ to $\mathrm{F}$ ).
For follow-up, the patient was seen 10 days after surgery. No discomfort was reported by any patient and wound healing was regular in all 10 cases. Neither infection nor any clinical signs of graft loss were noted. Sutures were removed 14 days after surgery.

No implant complications were observed during the osseointegration period.

\section{Histologic and Histomorphometric Analysis}

Biopsies were stored in a 10\% formalin solution and decalcified later in an ethylenediaminetetraacetic acid solution, sliced, and stained with hematoxylin/eosin. New bone, residual bone, and connective tissue formation were reported by histometric analysis, using a grid placed directly on the image slides.

\section{Statistical Analysis}

A computer statistical software program (SPSS 20.0, SPSS Inc, Chicago, Illinois, USA) was used to determine the descriptive statistics (mean, standard deviation [SD]). Data were presented as mean \pm SD and analyzed based on Kolmogorov-Smirnov and Shapiro-Wilk normality tests, using paired $t$ test. $p$ value $<0.05$ was considered significant.

\section{Results}

There was a statistically significant decrease in the linear clinical evaluation of the buccolingual width of the crest dimension after 5 months vs before extraction, whereas a statistically significant increase of the vertical height of the crest after 5 months vs before extraction was recorded. The horizontal alveolar ridge dimension had a mean width of $10.3 \mathrm{~mm}$ (SD 2.49) before extraction which decreased to $8.85 \mathrm{~mm}$ (SD 2.02) at T1 (5 months postsurgery). 

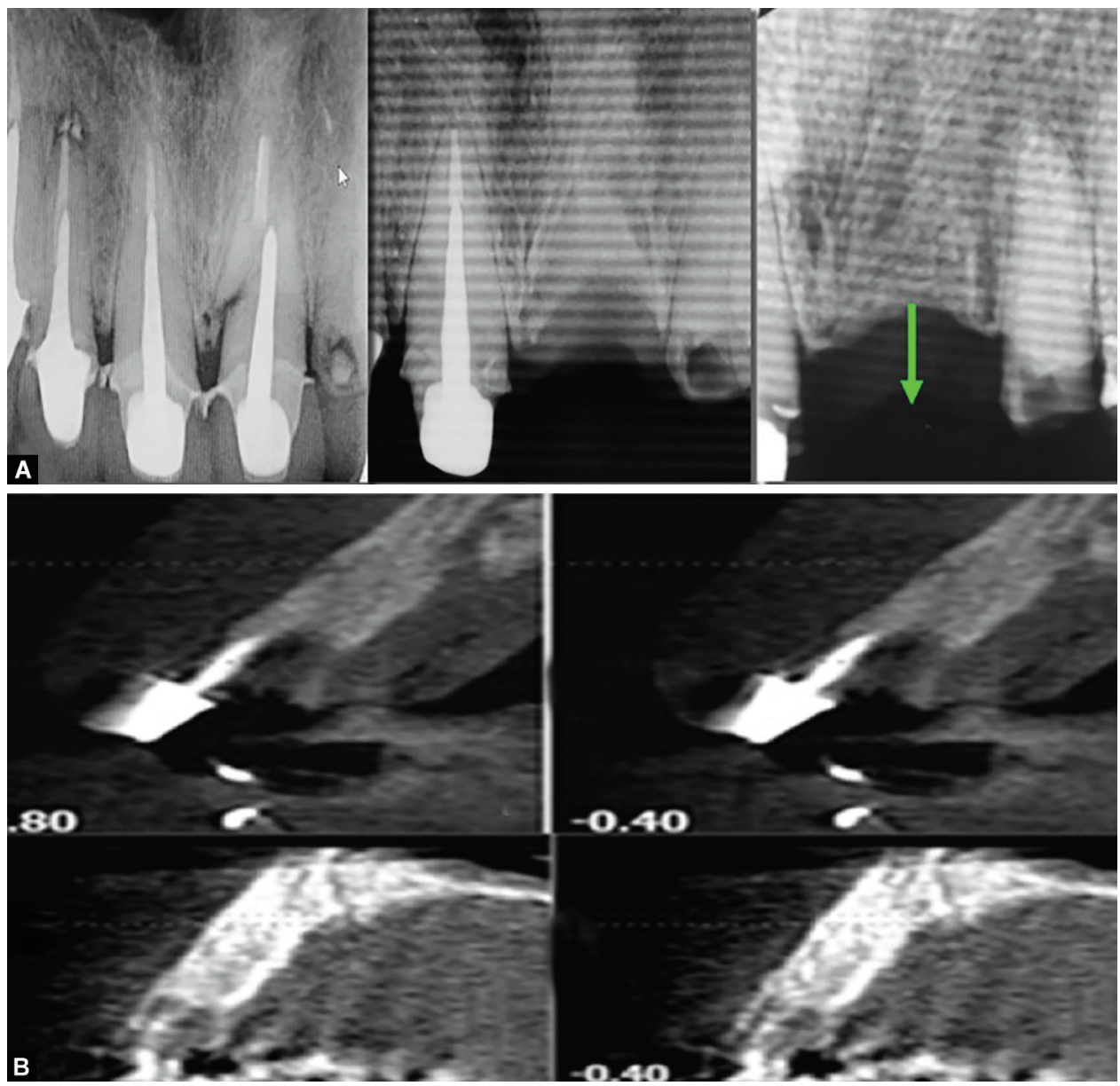

Figs 2A and B: (A) Intraoral radiographs: before extraction, after ARP, and at 5 months; (B) CBCT: before extraction and at 5 months
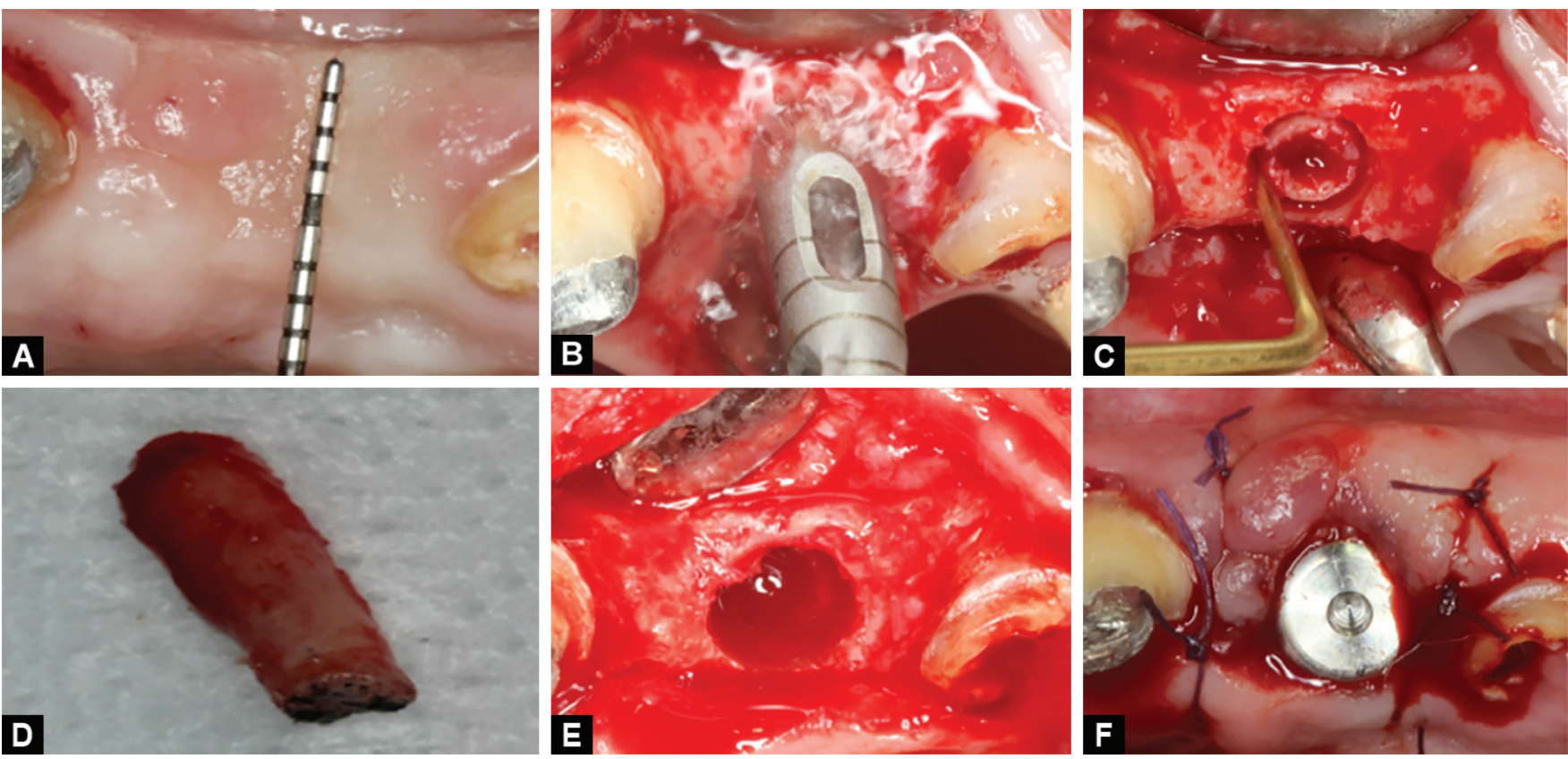

Figs 3 A to F: (A) Clinical appearance at 5 months; (B) Trephine bur used; (C) Core biopsy in situ; (D) Harvested biopsy; (E) Implant site preparation; (F) Implant placed in one-stage surgery 
For the vertical ridge dimensions, the initial ridge mean height was $11.25 \mathrm{~mm}$ (SD 1.25) and increased to $12.85 \mathrm{~mm}$ (SD 1.17) after 5 months. The vertical dimensional gain had a mean of $1.6 \mathrm{~mm}$ (SD $0.65 \mathrm{~mm}$ ) (Table 1).

The results showed a bone horizontal (EE") reduction mean value of $1 \mathrm{~mm}$ before extraction and after 5 months, respectively (7.55 \pm 1.42 vs $6.592 \pm 1.27)$. On the other hand, the mean bone height value ( $\left.A^{\prime} A^{\prime \prime}\right)$ was preserved before extraction and after 5 months, respectively $(8.743 \pm 1.48$ vs $8.521 \pm 1.08)$ (Table 2$)$.

Table 1: Horizontal and vertical changes of the crest before extraction and after 5 months

\begin{tabular}{lccl}
\hline Cases & $\begin{array}{l}\text { Before extraction } \\
(\mathrm{mm}) \text { T0 }\end{array}$ & $\begin{array}{l}\text { After 5 months } \\
(\mathrm{mm}) \mathrm{T1}\end{array}$ & $\begin{array}{l}\text { Variation } \\
(\mathrm{mm})\end{array}$ \\
\hline $\begin{array}{l}\text { Buccolingual } \\
\text { width }\end{array}$ & $10.3 \pm 2.49$ & $8.85 \pm 2.02$ & $-1.45 \pm 1.03$ \\
Vertical height & $11.25 \pm 1.25$ & $12.85 \pm 1.17$ & $1.6 \pm 0.65$ \\
\hline
\end{tabular}

Values are expressed as mean

Table 2: Radiological analysis showing two parameters: A'A" (vertical dimension) and EE" (horizontal dimension), values are expressed as mean

\begin{tabular}{lll}
\hline Parameters & $\begin{array}{l}\text { Means before } \\
\text { extraction }\end{array}$ & $\begin{array}{l}\text { Means after alveolar } \\
\text { ridge preservation }\end{array}$ \\
\hline A'A" $^{\prime}$ & $8.743 \pm 1.48$ & $8.521 \pm 1.08$ \\
EE" & $7.55 \pm 1.42$ & $6.592 \pm 1.27$ \\
\hline
\end{tabular}

For radiological measurements, there is no statistically significant difference of the radiological vertical bone height after 5 months vs before extraction in the whole conditions ( $A^{\prime} A A^{\prime \prime}, C^{\prime} C^{\prime \prime}$, $P Q$, and $R S)$. The findings of the radiological horizontal dimension decrease were considered significant after 5 months vs before extraction in the whole conditions (DD", EE", and FF") (Fig. 4).

Histology showed a new lamellar bone formation with small areas of woven bone. The new bone was mature, showing an organized matrix with a line of osteoblast at the periphery (Fig. 5).

The percentage of new bone formed was $42.44 \pm 5.54 \%$, the connective tissue was $48.62 \pm 8.66 \%$, and the remaining autogenous bone graft was also observed with a percentage of $8.94 \pm 5.28 \%$, with a new bone formed at the border evidence of active osteogenesis (Table 3 ).

\section{Discussion}

Maintaining bone level has been evaluated with different surgical techniques and different bone substitutes used to fill the alveolar defects after tooth extraction. 5,8,16,18,19

Studies evaluating bone dimensional changes after tooth extraction have shown that the ridge width alteration has an amount ranged between 17 and 60\%; however, ridge height is reduced by $1 \mathrm{~mm} .{ }^{1,24-26}$ Other studies presented an average of 3.8 and $1.24 \mathrm{~mm}$ of ridge reduction in width and height, respectively. ${ }^{27}$

Chappuis et al. ${ }^{28}$ related the amount of bone resorption to the ridge phenotype that depends greatly on the vestibular wall; they found 62.3 and $10.5 \%$ of bone resorption in vestibular and horizontal dimensions, respectively in the case of thin wall
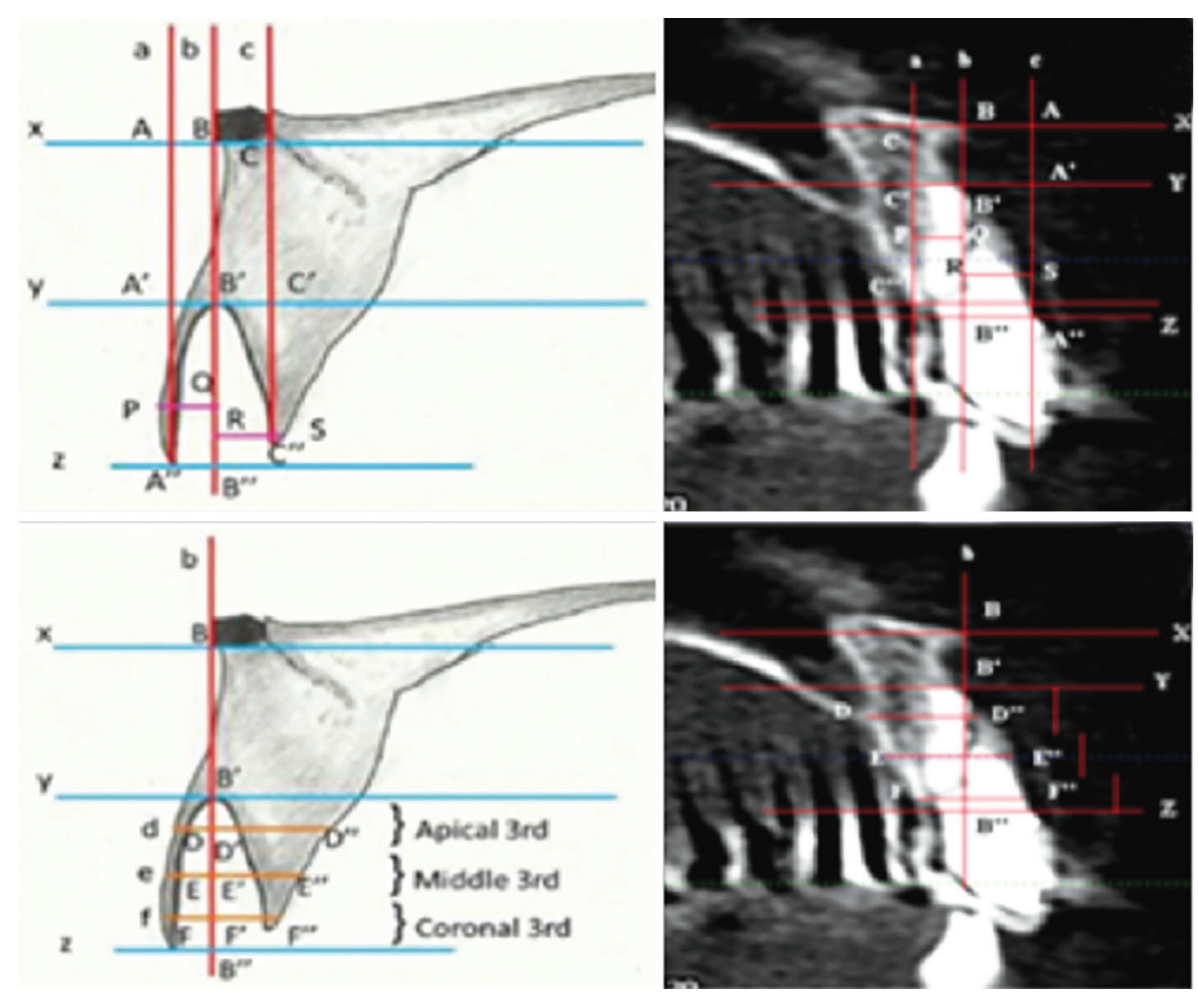

Fig. 4: Radiographic evaluation proposed by Das et al..$^{23}$
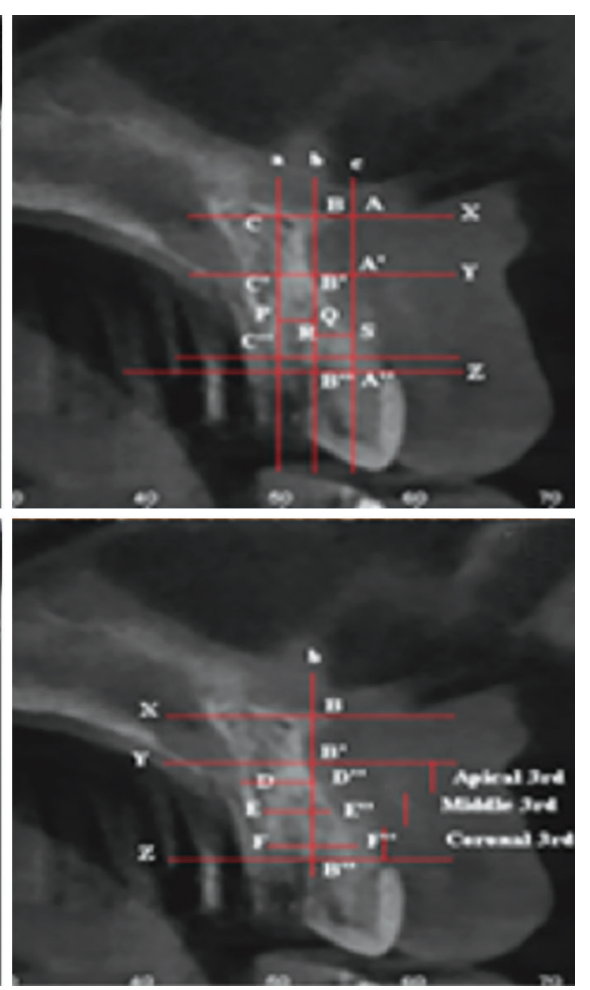

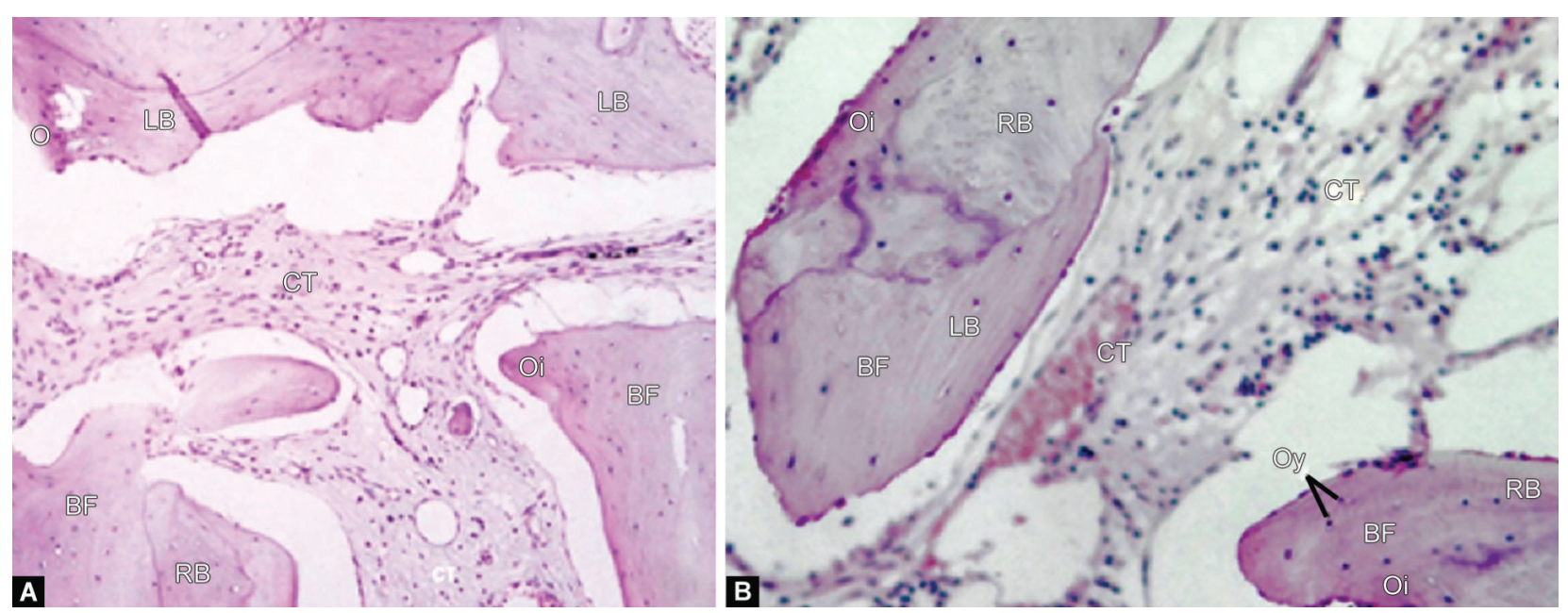

Figs $5 A$ and $B$ : Images $A$ and $B$ showing histological section with new bone formed (BF), lamellar bone (LB), connective tissue (CT), remaining bone graft (RB), osteoblasts (Ob), osteocytes (Oy), and osteoid (Oi); hematoxylin/eosin stain, image $(\mathrm{A}) \times 12.5$ magnification; $(\mathrm{B}) \times 25$ magnification

Table 3: Morphometric analysis of graft component, values are expressed as mean

\begin{tabular}{llll}
\hline $\begin{array}{l}\text { Histological } \\
\text { section }\end{array}$ & $\begin{array}{l}\text { Connective } \\
\text { tissue (\%) }\end{array}$ & $\begin{array}{l}\text { New bone } \\
\text { formed (\%) }\end{array}$ & $\begin{array}{l}\text { Residual bone } \\
\text { graft (\%) }\end{array}$ \\
\hline Mean & $47.93 \pm 9.76$ & $42.83 \pm 5.43$ & $9.24 \pm 6.4$ \\
\hline
\end{tabular}

phenotypes $(<1 \mathrm{~mm})$. However, no bone loss was observed in horizontal bone and $9.1 \%$ bone loss was observed in the buccal bone where the thickness of the buccal wall was greater than $1 \mathrm{~mm}$.

Araujo and Lindhe ${ }^{29}$ showed that bone loss was more pronounced in horizontal than vertical dimension; however, it was found that ridge dimensional contraction changes inside the socket itself; in the coronal portion of the socket, the bone loss is much more significant.

Chan et al. ${ }^{30}$ showed that using ARP techniques leads us to better outcomes compared to spontaneous healing. ARP procedures reduce bone loss and interfere with the modeling process, but we will always have bone loss, especially in the vestibular wall, because of the bundle bone concept and reduction of vascularization.

In comparing ARP to socket grafting techniques, Avila-Ortiz et al. ${ }^{31}$ described the results of a pooled quantitative analysis and revealed that sockets with spontaneous healing alone prevent horizontal 1.99 and vertical $1.72-\mathrm{mm}$ bone resorption, respectively.

The results obtained from the present pilot study with a mean horizontal dimension reduction of $1.45 \mathrm{~mm}(\mathrm{SD} 1.03 \mathrm{~mm}$ ) are in accordance with the previous reports of ARP via socket grafting, while vertical ridge dimension gain with a mean of $1.6 \mathrm{~mm}$ (SD $0.65 \mathrm{~mm}$ ) presents differences with the results found on the literature review.

The role of ARP is that the biomaterial has a scaffolding role that enhances the newly formed bone and the dimensions of the ridge were maintained and ridge contraction was compensated. ${ }^{29}$ Although we should mention that the final target after ARP procedures using autogenous bone is to obtain a high quantity of living bone with a less amount of hard and soft tissue loss and that is what our clinical, radiological, and histological results showed.
In the present study, an autogenous bone was used for its specificity of having living cells, and the osteogenic properties, pore granulometry, and interconnectivity of the graft are similar to the recipient site, which can have an important issue in accelerating the healing process with less inflammation and higher osteoblastic activity.

The histological results suggest that autologous grafts used have been resorbed in big percentage after 5 months while delivering the osteogenic property in favor of a big amount of new bone formation. When using xenograft in socket preservation, studies show an increase in the number of osteoclasts around the graft particles, which may decelerate the remodeling and the healing time. ${ }^{32}$

On the other hand, other studies show that a big amount of autologous particles has been resorbed and that the graft did not interfere with bone remodeling, leading to alveolar ridge resorption. ${ }^{19}$ These results were not in accordance with the results of the present pilot study. One explanation could be the fact that we used bone block graft comparing to the particulate used in the previous or other studies.

Since the bone core is inserted in a grade I socket with a four-wall defect, we will describe the graft as an inlay type of graft, demonstrated that bone grafts placed in the inlay position increased their volume over time; moreover, and due to their higher bone-to-bone contact, inlay bone grafts present a greater potential for revascularization, osteogenesis, osteoinduction, and osteoconduction. ${ }^{33-34}$

Another rationalization for the stability of the graft could be related to the addition of soft tissue punch covering the grafted site. ${ }^{29}$ Soft tissue augmentation adds more benefits to the grafting material in terms of ridge preservation; a study by Thalmair et al., ${ }^{35}$ comparing sockets with a free gingival graft in addition to xenograft and sites with xenograft alone, found more ridge preservation and less bone reduction when free gingival grafts are used.

For this reason, we chose in our study a soft tissue graft in addition to a hard tissue graft to add more benefits and reduce bone loss, knowing that the anterior zone is characterized by a thin vestibular wall; for this reason soft tissue dimensions increase 
after healing due to the rapid resorption of this thin facial bony wall, favoring the entrance of the soft tissue inside the socket. ${ }^{36}$ The choice of harvesting soft tissue from the tuberosity area was based on the quality of the graft, it is formed of dense collagen fibers covered by a well-keratinized layer. This could have a direct effect on the dimensional stability and the process of revascularization of the graft. ${ }^{37,38}$ Besides, soft tissues harvested from the tuberosity area heal faster with better color and contour, blending along with a lesser pain perception by the patient. ${ }^{38}$ One of the advantages of using a soft tissue graft is the full wound closure, which will contribute to a lesser amount of horizontal dimensional changes. ${ }^{21}$

Measurement of the recipient site is done from the opening of the socket at the level of the free gingiva till the apical part of the socket. The measurement must be done before the extraction of the tooth, knowing that the convexity of the root creates support to the buccal free gingiva; just following the tooth extraction, we will note a direct physical collapse of the nonsupported gingiva. In case the tooth is extracted in one piece, the measurement could be done outside the mouth directly on the root.

The second step of the measurement concerns the residual bone of the socket; knowing that the root presents a tapered anatomy that is narrower at the level of the alveolar bone comparing to the level of the free gingiva, a smaller diameter trephine will be used to harvest the autologous bone. The length of the bone core will depend on the depth of the socket; we must consider at least the one-third depth of the socket, knowing that the one-third of the coronal part of the socket is the most prompt for resorption. ${ }^{29}$

In addition, the rationale behind using the complementary drill for the preparation of the recipient site is to create adequate volume and a high bone-to-bone contact between the core bone graft and the alveolar recipient site. Besides, it will provide a high immobilization of the graft while excluding excessive pressure induced during inserting maneuver; knowing that the tapered anatomy of the root is different from the cylindrical shape of the trephine, the complementary drill will help in mimicking the bone core graft. Moreover, following the tooth extraction, the architecture of the harvested soft tissue graft helps prevent collapse of the nonsupported gingiva situated at the buccal-coronal part of the socket. This is not the case when the soft tissue graft is excluded.

\section{Conclusion}

Within the limitations of our study, despite the fact that in the anterior zone we have a thin vestibular wall that will resorb rapidly after tooth extraction, clinical and radiological results show that the punch of hard and soft tissue graft reduces hard and soft tissue dimensional alteration after tooth extraction. In addition, using autogenous tissues showed a histological new bone formation and a less amount of residual graft particles after 5 months following ARP, which seems to be an appropriate healing time.

More studies are needed for the rest of the alveolar classifications.

\section{Compliance with Ethical Standards}

Competing interests: None.

Ethical approval: All procedures performed in studies involving human participants were in accordance with the ethical standards of the institutional and/or national research committee and with the 1964 Helsinki declaration and its later amendments or comparable ethical standards.
Informed consent: Informed consent was obtained from all individual participants included in the study.

\section{References}

1. Schropp L, Wenzel A, Kostopoulos L, et al. Bone healing and soft tissue contour changes following single-tooth extraction: a clinical and radiographic 12-month prospective study. Int J Periodontics Restorative Dent 2003;23(4):313-323.

2. Van der Weijden F, Dell Acqua F, Slot DE. Alveolar bone dimensional changes of post-extraction sockets in humans: a systematic review. J Clin Periodontol 2009;36(12):1048-1058. DOI: 10.1111/j.1600051X.2009.01482.x.

3. Buser D, Martin W, Belser UC. Optimizing esthetics for implant restorations in the anterior maxilla: anatomic and surgical considerations. Int J Oral Maxillofac Implants 2004:19(Suppl.):43-61.

4. Stig $\mathrm{H}$, Anders $\mathrm{H}$. Alveolar ridge resorption after tooth extraction: a consequence of a fundamental principle of bone physiology. J Dent Biomech 2012;3:1758736012456543. Published online 2012 Aug 16. DOI: $10.1177 / 1758736012456543$.

5. Goh BT, Teh LY, Tan DBP, et al. Novel 3D polycaprolactone scaffold for ridge preservation - a pilot randomised controlled clinical trial. Clin Oral Implants Res 2015;26(3):271-277. DOI: 10.1111/clr.12486.

6. Araujo MG, Silva CO, Misawa M, et al. Alveolar socket healing: what can we learn? Periodontol 2000;2015:68(1):122-134. DOI: 10.1111/ prd.12082.

7 Schroeder HE. The periodontium. In: Oksche A, Vollrath L, editors. Handbook of microscopic anatomy. Berlin: Springer; 1986. p. 233-246.

8. Lekovic V, Camargo PM, Klokkevold PR. Preservation of alveolar bone in extraction sockets using bioabsorbable membranes. J Periodontol 1998;69(9):1044-1049. DOI: 10.1902/jop.1998.69.9.1044.

9. Scala A, Lang NP, Schweikert MT, et al. Sequential healing of open extraction sockets. An experimental study in monkeys. Clin Oral Implants Res 2014;25(3):288-295. DOI: 10.1111/clr.12148.

10. Januario $A L$, Duarte WR, Barriviera $M$, et al. Dimension of the facial bone wall in the anterior maxilla: a cone-beam computed tomography study. Clin Oral Implants Res 2011;22(10):1168-1171. DOI: 10.1111/j.1600-0501.2010.02086.x.

11. Morjaria KR, Wilson R, Palmer RM. Bone healing after tooth extraction with or without an intervention: a systematic review of randomized controlled trials. Clin Implant Dent Relat Res 2012;16(1):1-20. DOI: 10.1111/j.1708-8208.2012.00450.x.

12. El Chaar E, Oshman S, Fallah AP. Single-rooted extraction sockets: classification and treatment protocol. Compend Contin Educ Dent 2016;37(8):537-541.

13. Mardas N, Trullenque-Eriksson A, MacBeth $\mathrm{N}$, et al. Does ridge preservation following tooth extraction improve implant treatment outcomes: a systematic review: Group 4: Therapeutic concepts and methods. Clin Oral Implants Res 2015 Sep;26(Suppl. 11):180-201. DOI: 10.1111/clr.12639.

14. Masaki C, Nakamoto T, Mukaibo T, et al. Strategies for alveolar ridge reconstruction and preservation for implant therapy. J Prosthodont Res 2015 Oct;59(4):220-228. DOI: 10.1016/j.jpor.2015.04.005.

15. Sanz M, Cecchinato D, Ferrus J, et al. A prospective, randomized, controlled clinical trial to evaluate bone preservation using implants with different geometry placed into extraction sockets in the maxilla. Clin Oral Implants Res 2010;21(1):13-21. DOI: 10.1111/j.16000501.2009.01824.x.

16. Ferrus J, Cecchinato D, Pjetursson BE, et al. Factors influencing ridge alterations following immediate implant placement into extraction sockets. Clin Oral Implants Res 2010;21(1):22-29. DOI: 10.1111/j.16000501.2009.01825.x.

17. Jambhekar S, Kernen F, Bidra AS. Clinical and histologic outcomes of socket grafting after flapless tooth extraction: a systematic review of randomized controlled clinical trials. J Prosthet Dent 2015 May;113(5):371-382. DOI: 10.1016/j.prosdent.2014.12.009. 
18. Schnutenhaus S, Doering I, Dreyhaupt J, et al. Alveolar ridge preservation with a collagen material: a randomized controlled trial. J Periodontal Implant Sci 2018;48(4):236-250. DOI: 10.5051/ jpis.2018.48.4.236.

19. Araujo MG, Silva JCC, Mendonca AF, et al. Ridge alterations following grafting of fresh extraction sockets in man. A randomized clinical trial. Clin Oral Implants Res 2015;25(4):407-412. DOI: 10:1111/clr.12366.

20. Hjrting-Hansen E. Bone grafting to the jaws with special reference to reconstructive preprosthetic surgery. A historical review. Mund Kiefer Gesichtschir 2002;6(1):6-14. DOI: 10.1007/s10006-001-0343-6.

21. Araujo MG, Lindhe J. Dimensional ridge alterations following tooth extraction. An experimental study in the dog. J Clin Periodontol 2005;32(2):212-218. DOI: 10.1111/j.1600-051X.2005.00642.x.

22. Maiorana C, Poli PP, Deflorian M, et al. Alveolar socket preservation with demineralised bovine bone mineral and a collagen matrix. J Periodontal Implant Sci 2017;47(4):194-210. DOI: 10.5051/ jpis.2017.47.4.194.

23. Das $S$, Jhingran R, Bains VK, et al. Socket preservation by beta-tricalcium phosphate with collagen compared to platelet-rich fibrin: a clinico-radiographic study. Eur J Dent 2016;10(2):264-276. DOI: 10.4103/1305-7456.178298.

24. Osburn, RC. Preservation of the alveolar ridge: a simplified technique for retaining teeth beneath removable appliances. J Indiana State Dent Assoc 1974:53(1):8-11.

25. Barone A, Aldini N, Fini $M$, et al. Xenograft versus extraction alone for ridge preservation after tooth removal. A clinical and histomorphometric study. J Periodontol 2008;79(8):1370-1377. DOI: 10.1902/jop.2008.070628.

26. Iasella JM, Greenwell $\mathrm{H}$, Miller RL, et al. Ridge preservation with freeze-dried bone allograft and a collagen membrane compared to extraction alone for implant site development: a clinical and histologic study in humans. J Periodontol 2003;74(7):990-999. DOI: 10.1902/jop.2003.74.7.990.

27. Hammerle $\mathrm{CH}$, Araujo MG, Simion M. Evidence-based knowledge on the biology and treatment of extraction sockets. Clin Oral Implants Res 2012;23(Suppl. 5):80-82. DOI: 10.1111/j.1600-0501.2011.02370.x.
28. Chappuis V, Engel O, Reyes $\mathrm{M}$, et al. Ridge alterations post-extraction in the esthetic zone: a 3D analysis with CBCT. J Dent Res 2013;92(12 Suppl):195s-201s. DOI: 10.1177/0022034513506713.

29. Araujo MG, Lindhe J. Ridge alterations following tooth extraction with and without flap elevation. An experimental study in the dog. Clin Oral Implants Res 2009;20(6):545-549. DOI: 10.1111/j.16000501.2008.01703.x.

30. Chan $\mathrm{HL}$, Lin GH, Fu JH, et al. Alterations in bone quality after socket preservation with grafting materials: a systematic review. Int J Oral Maxillofac Implants 2013;28(3):710-720. DOI: 10.11607/jomi.2913.

31. Avila-Ortiz G, Chambrone L, Vignoletti F. Effect of alveolar ridge preservation interventions following tooth extraction: a systematic review and meta-analysis. J Clin Periodontol 2019;46(Suppl. 21):195223. DOI: 10.1111/jcpe.13057.

32. Araujo $M$, Linder $E$, Lindhe J. Effect of a xenograft on early bone formation in extraction sockets: an experimental study in dog. Clin Oral Implants Res 2009;20(1):1-6. DOI: 10.1111/j.16000501.2008.01606.x.

33. Sugg K, Rosenthal A, Ozaki W, et al. Quantitative comparison of volume maintenance between inlay and onlay bone grafts in the craniofacial skeleton. Plast Reconstruct Surg 2013;131(5):1014-1021. DOI: 10.1097/PRS.0b013e31828e217a.

34. Oppenheimer AJ, Tong L, Buchman SR. Craniofacialbonegrafting: Wolff's law revisited. Craniomaxillofac Trauma Reconstr 2008;1(1):4961. DOI: $10.1055 / \mathrm{s}-0028-1098963$.

35. Thalmair T, FickIS, Schneider D, et al. Dimensional alterations of extraction sites after different alveolar ridge preservation techniques - a volumetric study. J Clin Periodontol 2013;40(7):721-727. DOI: 10.1111/jcpe.12111.

36. Chappuis V, Engel O, Shahim K, et al. Soft tissue alterations in esthetic postextraction sites: a 3-dimensional analysis. J Dent Res 2015;94(9 Suppl):187S-193S. DOI: $10.1177 / 0022034515592869$.

37. Amin PN, Bissada NF, Ricchetti PA, et al. Tuberosity versus palatal donor sites for soft tissue grafting: a split-mouth clinical study. Quintessence Int 2018;49(7):589-598. DOI: 10.3290/j.qi.a40510.

38. Harris RJ. Histologic evaluation of connective tissue grafts in humans. Int J Periodontics Restorative Dent 2003;23(6):575-583. 